\title{
A Trama E O D RAMA NUMA Intervenção: AnÁlise SOB a Ótica DA PSICODINÂMICA DO TRABALHO
}

\author{
Maria Irene Stocco Betiol* \\ Maria José Tonelli**
}

RESUM O

\begin{abstract}
O
presente trabalho tem por objetivo apresentar os resultados de um processo de validação de consultoria em ergonomia e está organizado do seguinte modo: introduzimos o referencial teórico que norteia a discussão do trabalho, isto é, conceitos em Psicodinâmica do Trabalho (Dejours, 1992, 1994, 1997, 1999) tais como: espaço de palavra, prazer e sofrimento no trabalho, trabalho prescrito e trabalho real, que nortearão a análise dos resultados, bem como a idéia de validação de processos de intervenção em ambientes organizacionais; apresentamos, também, alguns conceitos da teoria psicanalítica de grupos segundo Bion (1970), necessários para a compreensão de processos que mobilizaram os grupos analisados. Na segunda parte, apresentamos o procedimento da coleta de dados, os atores e a trama, isto é, como os facilitadores conduziram a abertura de espaço de palavra, num primeiro momento, com o grupo da Empresa Cliente, depois com o grupo de consultores em Ergonomia e, em seguida, entre os dois grupos de atores envolvidos no processo. Na terceira parte, procedemos a uma discussão dos resultados da validação, confrontando os dados da experiência com a abordagem teórico-metodológica proposta e, finalmente, apresentamos considerações finais e encaminhamentos para trabalhos futuros.
\end{abstract}

ABSTRACT

his paper presents the results of a "validation process" in an ergonomics consulting project. The paper first introduces the theoretical basis for analysis of work, drawn from Psychodynamics of Work (Dejours, 1992, 1994, 1997, 1999), which includes concepts such as "space for communication", pleasure and suffering at work, prescribed work and real work, as well as the idea of validation of group research processes in work settings. Next, it will present some concepts from psychoanalytic group theory (Bion, 1970), necessary for understanding the processes that mobilize the groups analyzed. Next it will introduce the procedures for data collection, the actors and the drama - that is, how the facilitators enable the creation of a space for communication, with the group from the Client Company, then with the group of consultants in Ergonomics, and finally with both groups of actors. Following, this paper presents; the results of the "validation process", comparing the research data with the theoretical and methodological approach proposed, some concluding considerations and suggestions for consulting's work.

\footnotetext{
* Escola de Administração de Empresas de São Paulo-FGV

** Escola de Administração de Empresas de São Paulo-FGV
} 
presente artigo resulta da análise de uma intervenção em que os autores deste trabalho foram chamados a atuar como facilitadores para o processo de validação de um Projeto de Ergonomia, que envolveu a presença de dois grupos: os Consultores em Ergonomia e os representantes da Empresa Cliente, por ocasião do seminário de encerramento do referido projeto. A ação dos consultores em Ergonomia foi desenvolvida ao longo de um período de um ano junto à empresa Cliente, da Área de Serviços abrangendo todo o território nacional. Os facilitadores já haviam atuado no projeto de Ergonomia no seu início, como consultores para a área de Psicodinâmica do Trabalho, mas estavam afastados do dia-a-dia das ações práticas do projeto, o que permitia o distanciamento necessário para a atividade de validação. A participação dos facilitadores foi solicitada pela equipe de Consultores em Ergonomia e teve a concordância dos representantes da Empresa Cliente.

A validação que está referida neste trabalho, acompanha a proposta de Dejours (1996), para quem os procedimentos de validação, através dos quais se põem à prova algumas conjecturas, se aproxima mais de uma lógica da probabilidade do que de uma lógica de verificação empírica e só pode ser obtida através da palavra das pessoas que participaram da experiência conjunta. Neste sentido, validar não eqüivale a verificar. A verificação nunca é possível pois nenhuma equipe de intervenção poderá repetir, com o mesmo grupo, a mesma experiência que acabou de se realizar na medida em que este grupo não é mais o mesmo do início do processo. Ainda segundo Dejours, citando Ricoeur, "a validação é uma disciplina argumentativa comparável aos procedimentos jurídicos de interpretação legal. É uma lógica da incerteza e da probabilidade qualitativa (...) e se exerce no domínio da ação e das ciências humanas" (p.202,3). É a própria ação de transformação que está em pauta nesta abordagem e é, a partir da análise pós-fato da ação, de seus efeitos e de suas conseqüências sobre a situação, que se extrai conhecimento sobre o trabalho e sobre os seres humanos. (Dejours, 1996).

O tipo de validação proposto neste trabalho não parece ser um procedimento comum nas atividades de consultoria que, quando são apresentadas, tanto na mídia especializada como nas pesquisas acadêmicas, trazem relatos daquilo que foi positivo (ver, por exemplo, Zanelli, 1997) mas não apresentam, conforme citam Caldas. M. e Wood, T. 1999; Wood, 1997, as transgressões, as dificuldades, enfim os problemas enfrentados seja pelos consultores seja pelos clientes. Outro ponto a ser ressaltado, é que a discussão sobre a ação dos consultores tem se voltado mais para o papel que estes desempenham como difusores de modismos gerenciais (Abrahamson, 1991; Caldas, 1999) do que sobre a própria ação de consultoria. O artigo de Caldas (1999) é quase uma exceção neste cenário, ao mostrar as diferentes modalidades de ação de consultores. O autor argumenta que a relação consultor-cliente pode ser entendida como de exploração, de dependência ou de ajuda. Ao se tratar de uma relação de ajuda, a ação dos consultores pode ser interpretada através de diferentes metáforas como a de: fuzileiros, árbitros, facilitadores, educadores, médicos e psicanalistas. Ainda que o artigo explore bem os diferentes papéis dos consultores, os sofrimentos e as dificuldades enfrentadas, quer pelos consultores quer pelos clientes, ficam ocultos nos bastidores da intervenção e raramente discutidos tanto na mídia como no mundo acadêmico.

De modo geral, a ação dos consultores é sempre validada com a percepção de mudanças pelo cliente ou dos próprios consultores, mesmo quando o processo é descrito como participativo, como no trabalho de Naves, Mafra, Gomes e Amâncio, 2000, por exemplo. O processo de validação, efetuado por pessoas distanciadas das ações cotidianas da consultoria representa, no nosso entender, um modo ainda não muito utilizado no acompanhamento das transformações na empresa. O processo de validação, da forma como proposto por Dejours (1999), permite resgatar a ação e o papel dos consultores, bem como o prazer e o sofrimento dos envolvidos na tarefa. 
É nossa intenção neste trabalho mostrar os sofrimentos e os prazeres, bem como os objetivos alcançados pelos clientes e pelos consultores, a partir de um espaço de discussão aberto e cooperativo. Como três grupos de atores estão presentes nesta trama, eles serão identificados como: Empresa Cliente (EC) que constava do grupo composto por gerentes e executivos intermediários da empresa; o grupo dos consultores em Ergonomia (CE) e, ainda que desempenhando, neste processo e neste momento, o papel de consultores para o projeto de validação, os autores deste trabalho serão referidos como facilitadores (F) para não haver confusão com o grupo de consultores em Ergonomia.

Apresentamos, a seguir, a abordagem teórico-metodológica que norteou o trabalho de intervenção para na seqüência apresentar o trabalho de campo e a discussão de seus resultados.

\section{A Abordagem Teórico-M etodológica}

A Psicodinâmica do Trabalho (Dejours, 1994; Dejours, 1997; Dejours, 1999) é uma disciplina que surge no final dos anos 80 , como uma vertente crítica da abordagem francesa sobre a questão da relação homem-trabalho. A disciplina está apoiada nos conceitos psicanalíticos e se utiliza também dos estudos filosóficos de Habermas (1988), especialmente sobre a importância da ação comunicativa na construção da emancipação humana. A Psicodinâmica do Trabalho, enquanto disciplina, se revela essencialmente multidisciplinar, já que integra também conceitos da Medicina do Trabalho, da Ergonomia e da Psicologia.

Na concepção de Dejours $(1994 ; 1997 ; 1999)$ homens e mulheres estão sempre submetidos a pressões e sofrimento no trabalho, já que é sempre necessário um ajuste entre a subjetividade e a organização do trabalho. Mas é no exercício deste ajuste, exatamente que se coloca em prática a inteligência e a criatividade de cada um no trabalho. O uso desta inventividade, entretanto, precisa ter reconhecimento para que ela possa ser vivida como prazer e não como insatisfação. Para isso, Dejours $(1994,1997)$ considera fundamental a existência de um "espaço de palavra" que permita a troca, a exposição das dificuldades e da engenhosidade colocada pelo sujeito tendo por objetivo a produção e a produtividade.

\section{Sobre o prescrito e o real do trabalho}

Para Leplat e Hoc (1992), "toda análise de situação de uma perspectiva psicológica leva à interrogação sobre as relações entre uma tarefa e uma atividade: o que é solicitado do sujeito, o que ele busca fazer, o quê e como ele efetivamente o faz e, finalmente, quais são as relações entre estas questões?" (p.47).

Estas questões demandam uma explicitação entre "tarefa" e "atividade". Na acepção corrente, a tarefa indica aquilo que tem que ser feito e a atividade aquilo que é feito. A tarefa pré-existe à atividade e visa a orientar de forma mais completa ou de forma menos completa e é sempre descrita através de uma certa linguagem. Para uma mesma tarefa, muitas descrições são possíveis e haverá, sempre, algo de implícito pois, de um lado, nem todas as condições são passíveis de serem antecipadas e de outro, nem sempre a linguagem utilizada por aquele que prescreve a tarefa tem a mesma significação para aquele que vai executá-la. Segundo Clot (1998), " o operador se apresenta sob a figura de autor-intérprete no centro da cena do trabalho, ocupado em tecer sua ação com os fios de um significante que the dá um sentido" (p.211). Segundo Dejours (1997), " assumir as conseqüências do conceito de atividade nas pesquisas sobre o fator humano, é colocar na teoria do trabalho os conceitos de (resistência do) real, de revés (objetivo) e de compensação parcial do revés pelos processos que implicam a subjetividade e que decorrem de uma produção psíquica e cultural que procede da experiência verdadeira e não da experimentação regrada: a engenhosidade". (p. 45). Trabalhar é fazer a aproximação entre a tarefa prescrita e o real do trabalho, através da criatividade, engenhosidade e inteligência astuciosa, em interação social. A superação das resistências impeditivas 
para se atingir o real do trabalho é que permite a conversão de um sofrimento condição inevitável e ubíqua a todo ser humano -, em um sofrimento criativo, na transformação do sofrimento pelo sentido que Ihe foi dado. (Dejours, 1994).

\section{O modo de funcionamento dos grupos}

Todo trabalho em grupo, além da dimensão cognitiva com vistas à resolução de uma tarefa, apresenta outras dimensões que não podem ser relegadas a um segundo plano, sob o risco de não se atingir os objetivos propostos. Os relacionamentos interpessoais mobilizam emoções intensas, algumas mais conscientes e outras menos conscientes, que necessitam ser analisadas em suas mensagens simbólicas, para que se possa compreender o sentido das ações dos membros do grupo. Uma das abordagens teóricas, de base psicanalítica, com ênfase nos processos inconscientes dos grupos, foi desenvolvida por W.R. Bion (1970). Segundo o autor, a racionalidade do grupo é profundamente afetada pelas emoções e sentimentos irracionais de seus membros e o pleno potencial do grupo só se libera pelo reconhecimento e enfrentamento deste fato. Bion elabora sua teoria criando a expressão "pressupostos básicos de grupos". Os grupos, na interação de seus membros com vistas a uma tarefa, passam por três estados emocionais distintos dos quais se pode deduzir três pressupostos básicos: o pressuposto "luta-fuga", o pressuposto da "dependência" e o pressuposto da "formação de pares". Estes pressupostos emergem em razão das fantasias e temores dos membros dos grupos, diante de uma tarefa que se mostra complexa e que ultrapassa as possibilidades de resolução por parte de seus integrantes. Em cada um dos pressupostos, a relação entre o líder ou coordenador do grupo e seus integrantes se altera em função da inveja, das lutas pelo poder ou do sentimento de fragilidade de seus membros. A relação com os líderes pode variar de um sentimento de total dependência, em que o saber é integralmente depositado sobre o líder, passando pela disputa do lugar da liderança e a tentativa de aliciar os demais membros para desestabilizar a autoridade de liderança até a "formação de pares", isto é, a união de duas pessoas que se apoiam mutuamente e que ignoram os demais membros e o próprio líder, caracterizando, respectivamente, os pressupostos de "dependência", "luta-fuga" e "formação de pares".

Ainda que não seja possível esgotar neste texto a riqueza e o rigor dos conceitos da proposta da Psicodinâmica do Trabalho de C. Dejours e da Psicologia de Grupos desenvolvida por Bion, são os conceitos destas abordagens que estarão guiando a análise da intervenção que apresentamos a seguir.

\section{RELATO DAS EXPERIÊNCIAS: OS ATORES E A TRAMA}

Num seminário de três dias, que reuniu os atores em questão, isto é, o grupo de representantes da Empresa Cliente, o grupo de Consultores em Ergonomia e o grupo de facilitadores, foram realizadas 3 reuniões de grupos de discussão. A primeira reunião, que ocorreu entre os facilitadores e o grupo representante da empresa cliente, teve a duração de 4 horas. A segunda reunião ocorreu entre os facilitadores e o grupo de consultores em Ergonomia e teve a duração de 3 horas. A terceira reunião ocorreu entre os facilitadores, o grupo EC e o grupo CE e teve a duração de 3 horas. Neste terceiro momento, as atividades foram conduzidas pelos facilitadores que intermediaram as apresentações de um grupo para o outro, bem como os debates que se seguiram sobre as percepções, sentimentos e ressentimentos ainda não discutidos e os desgastes e ganhos com o projeto como um todo.

O objetivo do seminário era apresentar a totalidade das análises ergonômicas feitas em diversas unidades da empresa, bem como as sugestões de mudança propostas, encerrando as atividades do projeto de consultoria. Como o trabalho dos consultores em Ergonomia estava apoiado sobre a metodologia da pesquisaação de Thiollent (1997), o balanço referia-se às atividades realizadas em conjunto com o grupo da empresa cliente e não só às propostas dos consultores. Para 
esclarecer o modelo de intervenção usado pelo grupo de consultores em Ergonomia, cabe ressaltar que a pesquisa-ação nas organizações, tal como a propõe Thiollent (1997), considera que não é possível estabelecer uma proposta de intervenção baseada em receitas com objetivos decididos de modo unilateral pelos consultores. A proposta teórico-metodológica da pesquisa-ação inclui um diagnóstico participativo, com os objetivos da intervenção e suas propostas práticas debatidas entre os participantes e os membros da empresa. As soluções resultam da criatividade deste debate democrático e do compromisso de todos na implementação das mudanças. A metodologia da pesquisa-ação tem sido utilizada em movimentos sociais (Thiollent, 1985) e, quando dirigida para o espaço organizacional, pode causar temores quanto a alguma perturbação social (Thiollent, 1997) já que representa um desafio quando se considera o significado da expressão coletiva dos membros da empresa.

Apresentaremos a seguir, as atividades realizadas pelos facilitadores com a empresa cliente (EC), as atividades realizadas pelos facilitadores com os consultores em Ergonomia ( $C E)$ e, na seqüência, uma discussão sobre a dinâmica que se instalou entre os grupos.

\section{As Atividades com o Grupo Cliente - Coleta de Dados}

Na abertura dos trabalhos desta atividade, foi feita uma breve exposição dos objetivos, isto é, a validação do processo do Projeto de Ação Ergonômica, através da discussão de grupos. Enfatizou-se que a discussão não era sobre a teoria da Psicodinâmica do Trabalho ou sobre qualquer outra proposta técnica ou teórica, mas sobre o desenrolar do processo do projeto ergonômico. Estavam presentes neste trabalho dez membros da equipe técnica da empresa cliente. 0 trabalho teve a duração de quatro horas, durante as quais foram propostas várias atividades.

$\mathrm{Na}$ primeira delas, solicitou-se que cada participante fizesse uma lista com dez pontos - os de maior repercussão durante o projeto. Nesta primeira listagem não foi solicitada uma separação entre pontos fortes e fracos, para que os conteúdos pudessem fluir mais livremente. Na seqüência, as pessoas formaram três sub-grupos e elaboraram, a partir das listagens individuais, uma lista de consenso do grupo, sobre os pontos fortes e os pontos fracos do projeto

Como última atividade foi solicitado aos grupos que representassem em um desenho o processo do projeto. Os três desenhos foram afixados para comentários, análises e interpretações dos participantes. Se bem que extremamente significativos, os desenhos não serão analisados neste texto. Por uma necessidade de síntese, apresentaremos apenas as listas de consenso sobre os pontos fortes e pontos fracos do projeto. Elas estão sendo apresentadas num quadro 1, a seguir:

Quadro 1 - Síntese do grupo empresa Cliente

\begin{tabular}{|c|c|}
\hline Pontos Fortes & Pontos Fracos \\
\hline $\begin{array}{l}\text { - } \begin{array}{l}\text { Conhecimento de uma nova área: a } \\
\text { ergonomia }\end{array} \\
\text { Projeto pode alavancar melhorias na } \\
\text { ergonomia dos processos produtivos } \\
\text { Aprendizagem que possibilitará } \\
\text { desenvol-ver soluções para áreas } \\
\text { operacionais, equipamentos, lay-outs, } \\
\text { processos de tra-balho e visão crítica } \\
\text { - Troca de experiências e aprendizagem } \\
\text { numa equipe diversificada/acadêmicos } \\
\text { e profissionais } \\
\text { Participação/negociação dos } \\
\text { trabalhadores }\end{array}$ & $\begin{array}{l}\text { - } \quad \text { Autoritarismo da equipe de } \\
\text { consultores em ergonomia } \\
\text { - Falta de interação e } \\
\text { comprometimento entre os } \\
\text { membros da equipe da empresa }\end{array}$ \\
\hline
\end{tabular}


Como uma outra atividade, foi pedido aos participantes da Empresa Cliente que listassem as ações do projeto que tinham gerado prazer e sofrimento. Os resultados estão a seguir.

Quadro 2 - Prazer e sofrimento arrolados pelo grupo Cliente

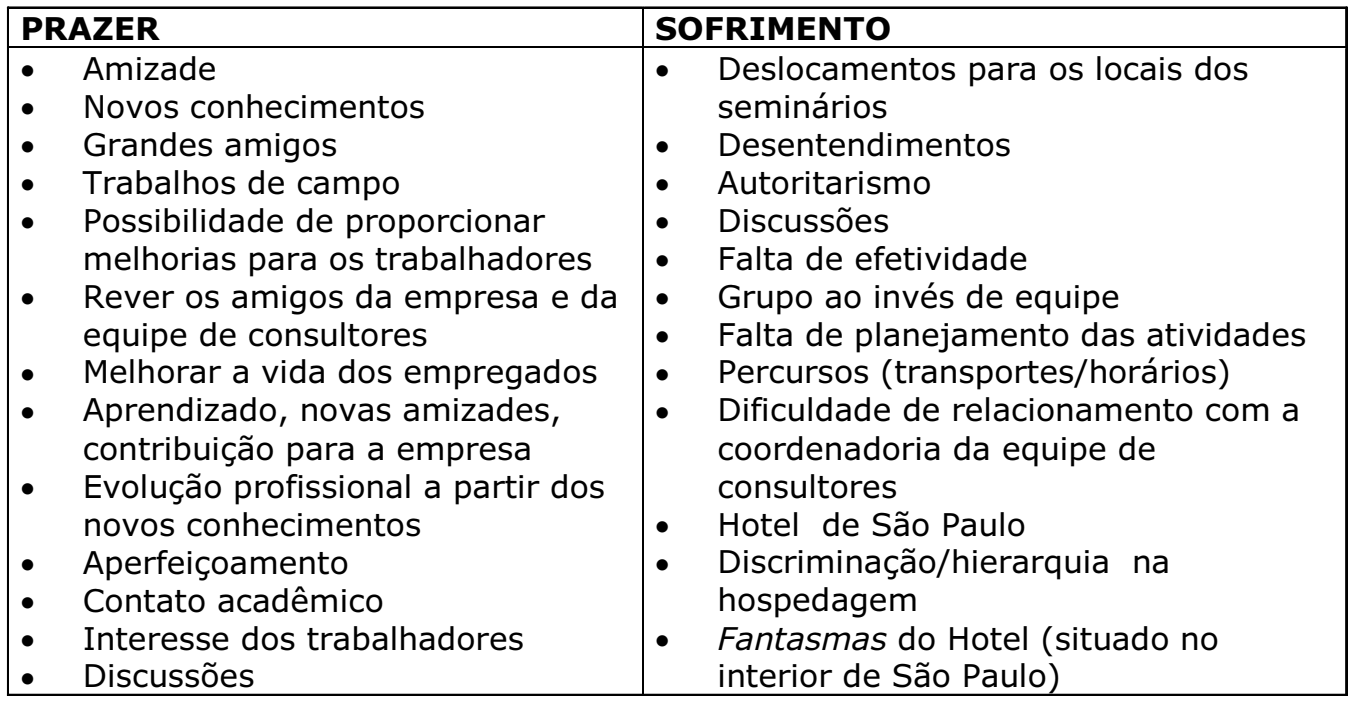

\section{Algumas considerações sobre as atividades deste grupo}

O conteúdo do trabalho dos sub-grupos, comparativamente às atividades realizadas individualmente, foi bem mais crítico. Os grupos radicalizaram nas críticas tanto naquelas feitas verbalmente como por escrito. Isto é esperado na medida em que, protegidos individualmente no anonimato do grupo, todos podiam expressar de modo mais contundente suas visões. De qualquer modo, a leitura da listagem individual mostrou pontos extremamente positivos em relação ao projeto, que não apareceram nos relatos dos sub-grupos. Nas listagens individuais é forte o reconhecimento de que o Projeto trouxe benefícios tanto individual como coletivamente.

Consideramos que é no "espaço de discussão" que a organização do trabalho do grupo pode ser analisada e eventualmente evoluir. O espaço de discussão dos sub-grupos e do grupo como um todo permitiu, de certa forma, uma catarse, uma liberação de emoções contidas. O aparecimento da palavra fantasma, ainda que fazendo parte de uma brincadeira do grupo e ligada à história do hotel onde estavam sendo realizadas as atividades, aponta para a necessidade de elaborar fantasmas, no sentido psicanalítico do termo. Será que os fantasmas do Projeto tiveram, neste espaço de discussão, condições de explicitação?

\section{As Atividades com o Grupo de CONSUltores EM ERGONOMIA}

As atividades com a equipe de consultores em ergonomia foram realizadas em moldes semelhantes ao grupo anteriormente descrito, ainda que não tenha sido pedido uma listagem individual sobre as repercussões do projeto. Formou-se subgrupos para discussão dos pontos fortes e fracos do projeto. Os resultados estão apresentadas no quadro 3 , a seguir: 
Quadro 3 - Síntese do grupo de consultores em Ergonomia

\begin{tabular}{|c|c|}
\hline Pontos Fortes & Pontos Fracos \\
\hline $\begin{array}{l}\text { - } \quad \text { Aumento do aprendizado } \\
\text { - } \quad \text { Trabalho em equipe interdisciplinar, } \\
\text { multidisciplinar e interinstitucional }\end{array}$ & $\begin{array}{l}\text { - } \quad \text { Cronograma apertado } \\
\text { - } \quad \text { Inserção de novas atividades não } \\
\text { planejadas }\end{array}$ \\
\hline
\end{tabular}

Foi pedido aos participantes que listassem os aspectos do projeto que tinham gerado prazer e sofrimento no decorrer do processo do projeto. Os resultados são apresentados a seguir:

Quadro 4 - Prazer e sofrimento arrolados pelo grupo de Consultores em Ergonomia

\begin{tabular}{|c|c|}
\hline Prazer & Sofri \\
\hline 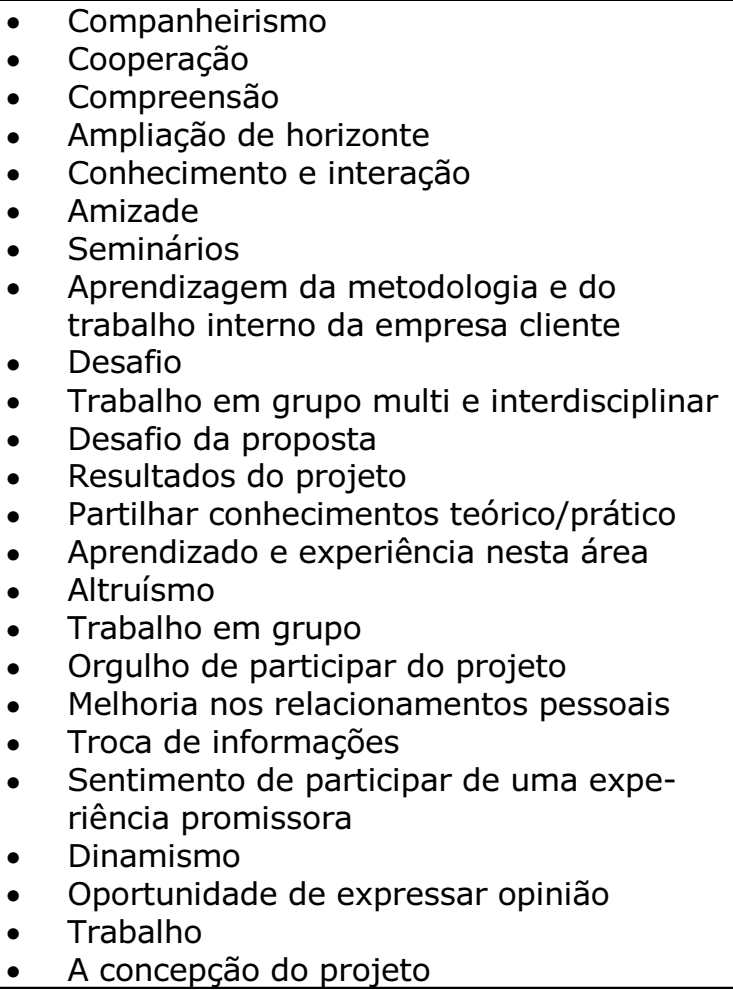 & 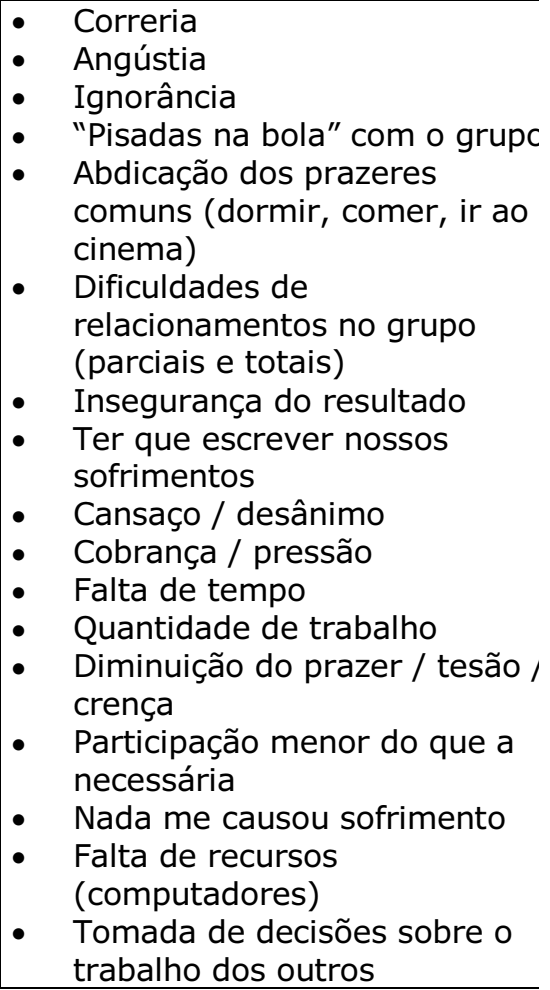 \\
\hline
\end{tabular}

\section{Observações sobre o grupo de Ergonomia}

Apesar das pressões que todo projeto acarreta, principalmente a tensão e o medo do enfrentamento de um modelo novo como o que foi proposto, o balanço entre pontos fortes e pontos fracos, foi positivo. A dificuldade maior parece estar relacionada com o lidar com grupos de trabalho e o relacionamento interpessoal, tanto para os Consultores em Ergonomia, quanto para o grupo Cliente. Cabe observar que enquanto o grupo de CE se percebia como tendo espírito de equipe, o grupo EC os percebiam como autoritários. 


\section{Discussão SOBRE A TRAM A dos ATORES EnVOLVIDOS:}

A PERcepção dos Facilitadores Sobre o D RAM A do

\section{TRABALHO DE GRUPO}

A complexidade da metodologia da pesquisa-ação em associação com a Análise Ergonômica do Trabalho em um projeto de intervenção, foi percebida e expressa tanto pela equipe de consultores em ergonomia como pelo grupo de representantes da empresa cliente. A dificuldade por parte da empresa cliente, foi quanto ao entendimento de como atuar diante de um processo não usual, não tradicional, de parceria com o grupo de intervenção e, principalmente, do entendimento da própria metodologia que implica sucessivas idas ao campo e retorno à teoria. Estas duas situações novas, geradoras de ansiedade, provocaram um comportamento de depositação, por parte dos clientes, de solução dos problemas na equipe de consultores, num movimento típico de um modelo de consultoria tradicional, em que os especialistas assumem o saber e os clientes se colocam na posição do não saber, semelhante ao "pressuposto básico de dependência" da teoria de Bion (1970). Neste modelo teórico de trabalho com grupos, o autor aborda a questão das lideranças e a necessidade de estarem preparadas para a contenção da ansiedade da equipe, de suas críticas, da desqualificação das competências das lideranças e dos especialistas. O modelo de intervenção com base na teoria de pesquisa-ação, não cumpre um papel tradicional de dar respostas a todos os problemas, mas propõe uma forma de trabalho de parceria e colaboração da equipe como um todo na tarefa de construção das soluções dos problemas. A não elaboração grupal destes momentos de ansiedade, fez emergir o "pressuposto luta-fuga", ainda dentro da ótica de Bion. Neste pressuposto, emerge a formação de subgrupos que disputam a liderança por não estarem satisfeitos com as lideranças oficiais. Os ataques às lideranças provocam o fechamento do diálogo e da abertura à crítica. Sem este espaço de discussão, os não-ditos crescem em importância e os fantasmas paralisam o desenvolvimento dos grupos de trabalho com o conseqüente boicote aos aspectos técnicos.

A postura defensiva e controladora por parte dos consultores, diante das críticas, é interpretada como autocracia. Porém, quer seja um estilo autocrático de condução de grupos, quer seja uma forma controladora de conduta, não deixa de ser uma defesa contra o temor de não dar conta do processo em andamento, cuja intensidade transborda e sobrecarrega a equipe de consultores.

A ausência, por parte dos Consultores em Ergonomia, de "contenção do grupo" - no sentido psicológico do termo, isto é, a capacidade de agüentar a frustração do grupo e o sentimento de falta de clareza dos pontos de partida e de chegada do projeto - gerou expressões do tipo "por que não disse antes que era assim", repetida inúmeras vezes neste seminário de encerramento. Emergiram, também, expressões que davam conta do sentimento de que, por mais que fizessem, não era o suficiente, gerando desmobilização e o sentimento de não reconhecimento dos esforços empreendidos, de ambas as partes, consultores e clientes, e sabemos como o reconhecimento dos esforços das equipes é importante para a mobilização e investimento energético no trabalho (Dejours, 1994, 1999).

A atividade grupal desenvolvida no seminário de encerramento parece ter tido efeitos catárticos mais positivos para a equipe da empresa cliente do que para a equipe dos consultores. As expressões do desejo de que o trabalho dos facilitadores talvez devesse ter sido realizado antes, foram inúmeras, culminando com uma demanda de introdução de trabalho de formação de equipe ou de grupo para os Seminários de Difusão do Projeto.

A efetividade do trabalho com os facilitadores, se deve, provavelmente, ao espaço aberto à discussão dos problemas interpessoais - oportunidade anteriormente dificultada pela grande dispersão das pessoas da empresa cliente, ao longo do território nacional. Esta dispersão impediu um contato sistemático para trocas sobre as ansiedades do trabalho. Mas ele não foi tão efetivo para a equipe de consultores, pois estes tinham a oportunidade de encontros mais freqüentes. 
Mesmo que a equipe de consultores não tenha se utilizado deste espaço (conforme foi expresso pelo próprio grupo), concretamente era um espaço que existia pela proximidade física das pessoas gerando, no grupo da empresa cliente, o sentimento de desbalanceamento de oportunidades de trocas dentro da equipe, comparativamente à equipe de consultores.

É reconhecida a importância da interação social na transmissão do conhecimento construído social, histórica e culturalmente. A proximidade social é, então, um elemento importante no processo. O grupo da empresa cliente sentiu e verbalizou esta carência e o sentimento de não eqüidade de possibilidades entre as duas equipes.

A falta de discussão contínua, verbalizada como um dos pontos fracos do projeto pela própria equipe de consultores, merece um tratamento diferenciado para os próximos eventuais grupos de trabalho. O espaço de discussão permanente deve contemplar não só os aspectos técnicos mas e, principalmente, o processo de grupo, num ir e vir constante entre os aspectos técnicos e objetivos, entre os aspectos subjetivos e interpessoais, que parecem terem sido os entraves mais significativos para um trabalho que se pretenda seja realizado com menor carga psíquica.

Um trabalho de validação do projeto de Ergonomia, como o que foi desenvolvido com cada uma das equipes, não visou os aspectos da racionalidade instrumental mas a elaboração do sofrimento ocasionado pelas pressões e dificuldades, ou seja, por um lado, em coordenar e transmitir uma metodologia nova e, por outro, apreender o significado do projeto e colocá-lo em ação. "Elaborar o sofrimento não significa anulá-lo, mas transformá-lo em sentido e eventualmente em prazer: o prazer da reapropriação do vivido pela ação". Dejours (1994:86).

Cabe ressaltar que tais análises foram apresentadas como devolutivas dos facilitadores aos dois grupos envolvidos no processo.

\section{DiscusSÃo SOBRE O TRABALHO DOS FACILITADORES E A VALIDAÇÃO DO PROJETO DA CONSULTORIA}

Nossa intervenção, nesta etapa do processo do projeto, enquanto especialistas em Psicodinâmica do Trabalho, foi no sentido de atuar como facilitadores da proposta de validação pela posição de terceiros na relação entre o grupo da empresa cliente e os especialistas em ergonomia e deveu-se ao fato de que, não obstante termos participado de uma das etapas teóricas do projeto - e, portanto, termos uma certa familiaridade com o mesmo - estávamos distanciados do dia-a-dia das ações técnicas, o que poderia propiciar maior liberdade de expressão do grupo.

A validação esperada pelos especialistas em ergonomia, e que nesta nossa intervenção se ateve às interpretações dadas pelo grupo da empresa cliente do projeto de ergonomia, levou em conta duas etapas do trabalho total: o diagnóstico da situação a ser transformada e as propostas de ação encaminhadas ao cliente. Na medida em que a equipe de especialistas em ergonomia também verbalizou seus sentimentos e dificuldades para levar a cabo tal projeto, foi possível obter-se um confronto de representações e a visão dos dois pólos desse trabalho de intervenção em Ação Ergonômica que teve a duração de aproximadamente um ano, isto é, de dezembro de 1998 a janeiro de 2000.

O processo de intervenção dos consultores em Ergonomia seguiu a metodologia da pesquisa-ação (Thiollent, 1997), gerou certa insegurança, pois se assentou num ir e vir constantes, de reformulações teóricas e verificações na prática, através do processo de projetação, proposta e orientação da ação, discussão conjunta, impactos gerados sobre o sistema cliente, correção conjunta dos rumos, nova proposta de ação. A insegurança, pela ausência de propostas normativas previamente planejadas, trouxe consigo certa agressividade como decorrência da frustração. Houve um sentimento, por parte da EC, de que o poder era desigual e unilateral e pertencia apenas aos consultores em ergonomia (CE) e de que estes estavam se negando a socializar os conhecimentos, gerando res- 
sentimento, por parte do sistema cliente, pela existência de um saber que thes estava sendo negado, expresso através de algumas frases: "por que não disseram antes que era assim? Faltou divulgação prévia sobre os acontecimentos dos eventos e deficiência no planejamento das atividades." Por outro lado os consultores em ergonomia tinham, também, que lidar com as incertezas do método e vivenciavam a frustração do não-reconhecimento dos esforços despendidos além do sentimento de que, por mais que tentassem, não satisfaziam o cliente. Algumas frases do trabalho de discussão em grupo ressaltam este sentimento: "a metodologia dificulta o planejamento gerando algumas incertezas e inseguranças; dificuldade de compreensão do global do projeto; sobrecarga de trabalho ocasionada pelo método etc."

A sensação do não reconhecimento (Dejours, 1999) gera desânimo diante de um trabalho que não pode ser sublimado e não permite a descarga de energia psíquica (Dejours, 1994) necessária ao equilíbrio e envolvimento para o prosseguimento do trabalho. Expressões como: "cansaço, desânimo, cobrança, pressão; dificuldades de relacionamentos no grupo; diminuição do prazer/tesão/crença; angústia etc.", dão conta destes sentimentos.

Por outro lado, e de forma aparentemente paradoxal, a co-construção, junto com o cliente, dos passos a serem desenvolvidos e da proposição de soluções, é que foi o ponto forte da metodologia da pesquisa-ação. Todavia, é necessário que este movimento seja percebido pelo cliente em sua extensão e complexidade, para que se reduza o sentimento de insegurança que o método pode causar. Isto poderia ter sido obtido se, ao longo do processo do projeto de ergonomia, outros espaços de discussão tivessem sido promovidos para que as dificuldades e os não-ditos pudessem ser minimizados e não parasitassem o entendimento das propostas de ação. Este desejo foi expresso, claramente, pelos membros dos dois grupos de discussão.

Dentro das propostas teóricas da Análise ergonômica do Trabalho e da Psicodinâmica do trabalho, a questão do Real do trabalho e de sua dificuldade de concretização, é de fundamental importância. O Real do trabalho só se revela durante a ação e pelo revés e impossibilidade da concretização da atividade proposta. Para os especialistas em ergonomia, o andamento do próprio projeto caracterizou-se como o Real de suas atividades. A relação com o sistema cliente foi o outro ponto do tripé que caracterizou o trabalho como um todo, com todas as dificuldades que os relacionamentos interpessoais implicam.

Enquanto consultores e no papel de facilitadores do processo de validação, circulamos na interface CE/SC; nosso "real do trabalho" foi a contenção psicológica dos dois grupos supra-citados. O prescrito, isto é, os passos que seriam dados durante os diferentes momentos do trabalho, foi planejado, antecipadamente, mas o real do trabalho só pôde ser aquilatado em sua amplitude e dificuldade, no ato mesmo dos eventos, isto é, durante os grupos de discussão. O ápice da ansiedade para os consultores em Psicodinâmica do Trabalho, se deu no momento da realização do intergrupo. A necessidade da contenção psicológica dos sofrimentos verbalizados anteriormente nos sub-grupos e os riscos de uma possível explosão da emocionalidade, de um lado, ou da recusa em participar, de outro, geraram momentos de angústia sobre a possibilidade de fracasso em face a duas variáveis distintas: uma de ordem mais racional, mais objetiva, que era o estímulo à participação do grupo e outra da ordem do emocional, ou seja, a contenção psicológica já explicitada.

Quando se abre um espaço de discussão, não se pode prever ou controlar os conteúdos que emergirão ou os ânimos dos interlocutores; tem-se que correr os riscos da escuta comprometida. Porém, a linguagem, a palavra e a narração, vitais para a Psicodinâmica do trabalho, só podem ser, respectivamente, analisada, franqueada e compreendida, através do espaço de discussão.

A intervenção, por nós levada a efeito, que caracterizou-se como um espaço de discussão, proposto aqui como espaço público como o entende Habermas (1988) e recentrado sobre a questão do trabalho, obedeceu a algumas normas éticas e metodológicas da teoria da Psicodinâmica do Trabalho, tais como:

- demanda e aquiescência prévia dos membros dos grupos de discussão, tanto para os trabalhos realizados com cada grupo, quanto para o posterior espaço de interlocução entre ambos; 
- devolutiva, aos dois grupos, dos conteúdos verbalizados pelos participantes dos mesmos, através de relatórios parciais;

- estabelecimento de relação de confiança prévia, construída entre os consultores em Psicodinâmica e os dois grupos participantes das discussões, condição sine qua non da livre expressão dos participantes;

- $\quad$ respeito à palavra e ao sofrimento expresso pelos grupos e intergrupo;

- escuta comprometida;

- elaboração de um relatório final, aos grupos envolvidos.

Não obstante os cuidados e as cautelas relativas à ética da intervenção, acima explicitadas, a proposta de discussão e validação não ficou isenta de certa dose de violência sobre os participantes; talvez apenas a tenha minimizado, pois como afirmam Cru e Berthet (1999), a mudança de representação é difícil de operacionalizar. Quando se solicita uma intervenção externa há sempre, por parte das pessoas que serão envolvidas, uma ambivalência em relação às suas representações atuais: se por um lado há o desejo de mudar e compreender a situação de forma diferente, há, ao mesmo tempo, um apego às representações existentes. As razões nem sempre são claras, mas as resistências sempre estarão presentes. Se o equilíbrio existente no momento da solicitação da intervenção foi difícil de ser construído no passado, tanto mais as resistências se farão presentes. Para os autores supra-citados, um trabalho de intervenção organizacional deve buscar confortar os interlocutores diante das escolhas feitas no presente, para que estes possam sair da situação de ambigüidade da demanda. "Escolha delicada e de violência de uma abordagem que expõe o cliente diante dos consultores, de seus pares e de outros parceiros sociais" afirmam Cru \& Berthet (1999: 75).

Mudando suas representações e seus discursos e arriscando uma nova palavra, construída a partir de novas representações, as pessoas estarão renunciando às suas defesas habituais. E é, igualmente, em função das defesas já construídas e estabilizadas que se deve levar em conta que o fracasso de uma intervenção pode significar o não-desejo, por parte do cliente, de uma verdadeira mudança. Pode haver, até inconscientemente, o boicote ao sucesso da intervenção como uma forma de esquiva à mudança, que nunca é sem sofrimento. Encontrar um responsável externo à organização para culpabilizá-lo pelo fracasso da mudança, pode ser uma estratégia de defesa contra o sofrimento. Qualquer fórmula de solução de problemas construída a priori e externa ao grupo que será implicado na intervenção, está fadada ao fracasso por não ter sido subjetivada e co-construída com o grupo. E como já foi enfatizado, esta co-contrução de soluções é o ponto forte da metodologia da pesquisa-ação, mas não é, necessariamente, garantia de seu sucesso.

A linguagem foi outra questão relevante nesta experiência: a complexidade da linguagem técnica dos especialistas em ergonomia, nem sempre foi dominada pelos clientes, e gerou insatisfações claramente verbalizadas e referidas como: "utilizaram termos muito técnicos". As distorções comunicativas decorrem dos jargões que são típicos de alguns campos do conhecimento mas que não são necessariamente entendidos ou compartilhados por especialistas de outros campos de conhecimentos. No caso em questão, a linguagem dos engenheiros e a linguagem dos gestores foi permeada por um déficit semiótico gerador de mal-entendidos e conflitos.

Não estamos excluídos, enquanto consultores em Psicodinâmica do TrabaIho, de termos introduzido, tanto nos relatórios escritos quanto nas devolutivas e assinalamentos verbais, expressões ou apontamentos que talvez tenham sido interpretados segundo experiências pessoais dos grupos em questão e distanciadas de nossas reais intenções.

A intervenção ergonômica em questão, não se restringiu às dimensões cognitiva e instrumental, mas incluiu, também, a dimensão que Dejours (1996) denomina de pática, isto é, a vivência afetiva nas relações de trabalho ("pessoas foram ofendidas"). Para o autor citado, é esta dimensão que "está na origem de vivências variadas de prazer e sofrimento" (p.209). O prazer facilita a expressão e a verbalização do que é vivido no trabalho e o sofrimento, em contrapartida, faz 
surgir as defesas contra o sofrimento e que se tornam, por sua vez, empecilhos para a verbalização e a comunicação das relações subjetivas no trabalho. Reduzem o sofrimento, mas também impedem a percepção daquilo que está levando ao sofrimento no trabalho e, em decorrência, a possibilidade de mudança. Na proposta da Psicodinâmica do trabalho, o sofrimento nunca é eliminado, mas pode ser elaborado "para transformá-lo em sentido e eventualmente em prazer: o prazer da reapropriação do vivido pela ação". Dejours (1994:86).

\section{CONSIDERAÇÕES FINAIS}

O trabalho de facilitador de uma validação, realizado com base no modelo teórico da Psicodinâmica do Trabalho, constituiu-se, por si só em uma ação de intervenção cujo objetivo foi a análise da possibilidade de mudança de representação a respeito da Cultura de Ergonomia por parte de um Sistema Cliente . Nos demandou, enquanto especialistas em Psicodinâmica do Trabalho, um investimento psíquico significativo pois introduziu um espaço de discussão, mediatizado pela palavra entre ergonomistas e gestores e caracterizado como espaço de escuta comprometida e arriscada. O campo de trabalho estava, de certa forma, impregnado de incertezas, resistências, dúvidas, depositações de processos imaginários, inerentes aos grupos humanos, ou seja, de formas de sofrimento contidas e não verbalizadas anteriormente, que puderam ser explicitadas. Isto só foi possível, e diríamos, só é possível nas ações de intervenção, através da palavra dos participantes e em um ambiente de franqueza mútua, que não deve ser confundido com desrespeito, entre as partes envolvidas.

Projetos de intervenção, mesmo que tenham como foco central questões técnicas, operacionais e objetivas, não podem prescindir de espaços de discussão e análise das questões subjetivas e interpessoais sob pena de gerarem entraves ao trabalho como um todo e aumento significativo da carga psíquica das pessoas que dele façam parte.

O modelo de intervenção proposto pelos especialistas em ergonomia, objetivando a mudança da cultura de ergonomia, não foi um modelo funcionalista visando outra forma de comportamento dos participantes, tentando formatar os sujeitos para uma ação mais conforme a uma proposta das lideranças organizacionais. Ao contrário, buscou criar um espaço de subjetivação e de resignificação do projeto de ação ergonômica como um todo, porém, não isento de sofrimento.

Cabe considerar que tanto a atuação dos consultores em ergonomia como a atuação dos facilitadores estão mais próximas daquilo que Caldas (1999) denominou de relação de consultoria de ajuda, modelo de intervenção mais apoiado na concepção psicanalítica. Mas a abordagem de Dejours (1997), ao propor o conceito de "espaço de palavra", de um espaço público de discussão, ainda que apoiado na abordagem da psicanálise e, portanto, de uma mobilização subjetiva, está também apoiada na dimensão social que envolve a cooperação entre as partes e a compreensão do outro. Em outras palavras, a abordagem dejouriana incorpora um espaço político de discussões. Não se trata de obter nas consultorias e nas ações de mudança nas organizações nem um modelo ideal de comportamento humano nem um modelo ideal de organizações, mas da possibilidade de incluir a diversidade da criatividade das pessoas singulares com o objetivo do melhor funcionamento do coletivo. O prazer e o sofrimento no trabalho, na atividade dos consultores e no cotidiano das organizações sempre andam juntos.

Além disso, mesmo que as ações dos consultores não sigam a abordagem psicanalítica ou o modelo da pesquisa-ação, a explicitação dos passos dados na construção de mudanças na organização ou dos reveses enfrentados, são essenciais para o rigor necessário às intervenções. Não sendo assim, tudo pode parecer simplesmente mágica ou carisma do consultor. 


\section{REFERENCIAS BIBLIOGRÁfICAS}

ABRAHAMSON, E. Managerial fads and fashions: the diffusion and the rejection of innovations, Academy of Management Review, 16: 586-612, 1991.

BION, W. Experiências com Grupos. Os fundamentos da Psicoterapia de Grupo. Rio de Janeiro: Imago Editora, 1970.

CALDAS, M. Faça o que eu digo, mas não faça o que eu faço: pesquisa empírica sobre a adoção interna de serviços de consultoria por empresas de consultoria no Brasil. In: CALDAS, M e WOOD, T. Transformação e Realidade Organizacional: uma perspectiva brasileira. São Paulo: Ed. Atlas, 1999.

CALDAS, M e WOOD, T. Transformação e Realidade Organizacional: uma perspectiva brasileira. São Paulo: Ed. Atlas, 1999.

CLOT, Y. Le Travail sans I'homme? - Pour une psychologie des milieux de travail et de vie. Paris: La Découverte, 1998.

CRU, D. \& BERTHET, M. Les Violences de L'Intervention Em Entreprise. Le deuxième Colloque International de Psychodinamique et Psychopathologie du Travail: Violence et Travail. Paris: Le Laboratoire de Psychologie du Travail du CNAM em collaboration avec le Comité Scientifique de la revue TRAVAILLER, 1999.

DEJOURS, C. Psicodinâmica do Trabalho. Contribuições da Escola Dejouriana à Análise da Relação Prazer, Sofrimento e Trabalho. São Paulo: Atlas Ed., 1994.

DEJOURS, C. Épistémologie concrète et ergonomie. In: DANIELLOU, F. (sous la direction de) L'ergonomie em quête de ses principes - Débats épistémologiques. Tolouse: OCTARES Éditions, 1996.

DEJOURS, C. O Fator Humano. Rio de Janeiro: Ed. da Fundação Getúlio Vargas, 1997.

DEJOURS, C Conferências Brasileiras: Identidade, reconhecimento e transgressão no trabalho. São Paulo: Edições FUNDAP: EAESP-FGV, 1999.

HABERMAS, J. Teoria de la Acción Comunicativa - Crítica de la Razón Funcionalista. Madrid: Altea, Taurus, Alfaguara, S. A . , t.1 e 2, 1988.

LEPLAT, J. \& HOC, J. M. Tâche et Activité dans L'Analise Psychologique des Situations. In: LEPLAT, J. (coordinateur). L 'Analyse du Travail em Psychologie Ergonomique. Toulouse: OCTARES Editions, 1992, t.1.

NAVES, F.L., MAFRA, L.AS., GOMES, M.AR., AMÂNCIO, R. Diagnóstico organizacional participativo: potenciais e limites na análise de organizações. In: $0 \& S$, v.7 - no. 19, Set/Dez 2000, p.53-66

THIOLLENT, M. Metodologia da Pesquisa-ação. São Paulo: Ed. Cortez, 1985.

THIOLLENT, M. Pesquisa-ação nas organizações. São Paulo: Ed. Atlas, 1997.

WOOD, T. Mais leve que o ar: gestão empresarial na era de gurus, curandeiros e modismos gerenciais. São Paulo: Ed. Atlas, 1997.

ZANELLI, J.C. Estudo do Desempenho Pessoal e Organizacional: Bases para o Desenvolvimento de Equipes de Consultores. RAC, v.1, n.2, Maio/Ago 1997: 121-143 